\title{
The Effect of Intrahippocampal Injection of Group II and III Metobotropic Glutamate Receptor Agonists on Anxiety; the Role of Neuropeptide $Y$
}

\author{
Maria Śmiałowska*,', Joanna M Wierońska', Helena Domin' and Barbara Zięba' \\ 'Department of Neurobiology, Institute of Pharmacology, Polish Academy of Sciences, Kraków, Poland
}

\begin{abstract}
Earlier studies conducted by our group and by other authors indicated that metabotropic glutamatergic receptor ( $\mathrm{mGluR}$ ) ligands might have anxiolytic activity and that amygdalar neuropeptide Y (NPY) neurons were engaged in that effect. Apart from the amygdala, the hippocampus, another limbic structure, also seems to be engaged in regulation of anxiety. It is rich in mGluRs and contains numerous NPY interneurons. In the present study, we investigated the anxiolytic activity of group II and III mGluR agonists after injection into the hippocampus, and attempted to establish whether hippocampal NPY neurons and receptors were engaged in the observed effects. Male Wistar rats were bilaterally microinjected with the group II mGluR agonist (2S, I'S,2'S)-2-(carboxycyclopropyl)glycine (L-CCG-I), group III mGluR agonist O-Phospho-L-serine (L-SOP), NPY, the YI receptor antagonist BIBO 3304, and the Y2 receptor antagonist BIIE 0246 into the CAI or dentate area (DG). The effect of those compounds on anxiety was tested in the elevated plus-maze. Moreover, the effects of L-CCG-I and L-SOP on the expression of NPYmRNA in the hippocampus were studied using in situ hybridization method. It was found that a significant anxiolytic effect was induced by L-SOP injection into the CAI region or by L-CCG-I injection into the DG. The former effect was inhibited by BIBO 3304, the latter by BIIE 0246. NPY itself showed antianxiety action after injection into both structures. In the CAI area, the effect of NPY was prevented by BIBO 3304, whereas in the DG by BIIE 0246. Both the mGluR agonists L-CCG-I and LSOP induced a potent increase in NPYmRNA expression in the DG region of the hippocampal formation. The obtained results indicate that group II and III mGluR agonists, L-CCG-I and L-SOP, as well as NPY display anxiolytic activity in the hippocampus, but act differently in the CAI and DG. It was observed that group III mGluRs and $Y$ I receptors were engaged in the response in the CAI area, whereas group II mGluRs and $Y 2$ receptors played a pivotal role in the DG region.

Neuropsychopharmacology (2007) 32, I242- 1250. doi:I 0. I038/sj.npp. I 30 I258; published online 29 November 2006
\end{abstract}

Keywords: metabotropic glutamate receptors; hippocampus; anxiety; neuropeptide $Y$

\section{INTRODUCTION}

Anxiety-related disorders are a common disease imposing a significant social burden. At present, pharmacotherapy of these disorders is based mainly on benzodiazepines (BZDs). However, BZDs are not free of side effects, such as sedation, motor disturbances or nausea. Moreover, dependence and tolerance develop after a prolonged treatment (ChojnackaWójcik et al, 2001). Recent experimental studies have shown that ligands of metabotropic glutamatergic receptors (mGluRs) may also regulate anxiety level. Metabotropic GluRs are a group of receptors that bind glutamate, the most abundant excitatory neurotransmitter (Pin and

*Correspondence: Dr M Śmiałowska, Department of Neurobiology, Institute of Pharmacology, Polish Academy of Sciences, Smętna Street 12, 31-343 Kraków, Poland, Tel: + 48126623 288, Fax: + 4812637 45 00, E-mail: nfsmialo@cyf-kr.edu.pl

Received 3 February 2006; revised 25 September 2006; accepted 25 September 2006
Duvoisin, 1995). Ionotropic glutamatergic receptors show similar glutamate-binding properties. Antianxiety-like effects were observed after the mGluR5 antagonist MPEP or the mGluR group II agonist LY354740, injected systemically to rats (Pilc et al, 2002; Chojnacka-Wójcik et al, 2001), after the intrahippocampal injection of others group I mGluR antagonists (Chojnacka-Wójcik et al, 1997) and after group II and III mGluR agonists (Tatarczynska et al, 2001, 2002; Palucha et al, 2004).

Our earlier studies showed that the amygdala was an important structure participating in the antianxiety action of MPEP and of group II and III mGluR agonists. Moreover, neuropeptide Y (NPY) neurons and receptors took part in that effect (Wierońska et al, 2003, 2005). NPY in the amygdala has been postulated to be a potent, endogenous anxiolytic (Heilig et al, 1993), as anxiolytic-like effects were observed after intraamygdalar NPY microinjection. Our previous results indicated that NPY neurons in the amygdala were regulated by Glu transmission, and that mGluRs were engaged in this regulation, as mGluR ligands 
changed the expression of NPY and/or NPYmRNA in that structure (Wierońska et al, 2003, 2005).

The hippocampal formation is a limbic structure, which is also engaged in the regulation of anxiety (Gray, 1982; Eichenbaum et al, 1992; Vianna et al, 2004; Kalisch et al, 2006). It contains numerous NPY interneurons and is rich in mGluRs (Kohler et al, 1986; Redrobe et al, 1999; Dumont et al, 1998). It was revealed that the enhancement of glutamatergic transmission strongly stimulated NPY synthesis and/or increased the content of that peptide in the hippocampus (Śmiałowska et al, 2003; Bellmann et al, 1991; Schwarzer et al, 1996). Thus, it seemed of interest to find out whether anxiolytically active mGluR ligands could regulate NPY neurons in the hippocampal formation and whether such an interaction was engaged in their antianxiety effects. Our earlier findings indicated that group II and III mGluR agonists $\left(\left(2 \mathrm{~S}, 1^{\prime} \mathrm{S}, 2^{\prime} \mathrm{S}\right)-2\right.$-(carboxycyclopropyl)glycine (L-CCG-I) and O-Phospho-L-serine (L-SOP)) induced an increase in the expression of NPY-immunoreactivity in the hippocampus, as demonstrated by a radioimmunoassay (RIA) method (Śmiałowska et al, 2002). Therefore, in the present study, we examined the effects of two mGluR agonists, L-CCG-I (group II agonist) and L-SOP (group III agonist), after intrahippocampal administration, on anxiety and NPYmRNA expression in that structure. Moreover, we tried to find out whether the anxiolytic effects of those compounds were dependent on NPY transmission. Studies with mGluR ligands aimed to assess their potential, as future anxiolytic drugs seem to be important, as it is anticipated that they may not elicit tolerance and dependence, unlike BZDs. This is because some previous studies concerned with mGluR5 antagonists with anxiolytic activity (MPEP and MTEP) showed that those compounds did not engage BZD receptors, acted via NPY neurons, and at least MPEP did not induce tolerance after prolonged treatment (Kłodzińska et al, 2004; Wierońska et al, 2004; Pilc et al, 2002).

\section{MATERIALS AND METHODS}

\section{Animals}

Male Wistar rats weighing 200-230 g at the beginning of experiments were used. The animals were obtained from a local breeding farm. The rats were age-matched, and were housed six to a cage under a 12:12 light-dark cycle, with free access to food and tap water. The rats after cannulae implantation were housed singly. During the experiment, all efforts were made to minimize the animals' suffering and to reduce the number of animals used, in accordance with the Local Bioethical Commission Guide for the Care and Use of Laboratory Animals.

\section{Drugs}

(1) L-CCG-I, (Tocris), an agonist of group II mGluRs; (2) L-SOP (Tocris), an agonist of group III mGluRs; (3) NPY (Sigma); (4) BIBO 3304 ((R)- $N$-[[4-aminocarbonylaminomethyl) phenyl] methyl]-N2-(diphenylacetyl)-argininamide trifluoroacetate) (Boehringer-Ingleheim, Biberach, Germany), a Y1 receptor antagonist; (5) BIIE 0246 ( $N-[(1 S)$ 4-[(Aminoiminomethyl)amino]-1-[[[2-(3,5-dioxo-1,2-diphe- nyl-1,2,4-triazolidin-4-yl)ethyl]amino]carbonyl]butyl]-1-[2[4-(6,11-dihydro-6-oxo-5H-dibenz[b,e]azepin-11-yl)-1-piperazinyl]-2-oxoethyl]-cyclopentaneacetamide (Tocris), a Y2 receptor antagonist; (6) control rats received similar volumes of solvent.

All the compounds were dissolved in distilled water, their $\mathrm{pH}$ was adjusted to 7.4 with $\mathrm{NaOH}$ or $\mathrm{HCl}$ when necessary. All drugs were injected bilaterally into the hippocampus.

\section{Cannulae Implantation and Histology}

The rats were anesthetized with Equitesin and were stereotaxically bilaterally implanted with chronic guide cannulae aimed at the dorsal hippocampus CA1 or dentate area (DG) (dentate gyrus) region, $2 \mathrm{~mm}$ above the injection sites. The guide cannulae (23-gauge stainless steel tubing), secured by dental cement, were anchored to the skull by three stainless steel screws. In order to prevent clogging, stainless steel stylets were placed in the guide cannulae and left until the animals were microinjected 5-7 days later. The rats were adapted to handling, and on the test day the stylets were withdrawn and replaced with injection cannulae ending $2 \mathrm{~mm}$ below the tip of the guide cannulae. The coordinates for injection sites were: $\mathrm{A}+5.7, \mathrm{~L} \pm 2.1, \mathrm{H}+7.2$ (for injections into the $\mathrm{CA} 1$ ), and $\mathrm{A}+5.7, \mathrm{~L} \pm 1.6, \mathrm{H}+6.3$ (for injections into the DG) measured from the interaural line according to Paxinos and Watson stereotaxic atlas (Paxinos and Watson, 1986). On completion of each experiment, the rats were killed, their brains were removed, fixed in formalin, and injection sites were verified in coronal sections. Only animals with the correct injection sites were taken for a further analysis.

\section{Behavioral Studies: Plus-Maze Procedure}

Plus-maze test was carried out according to the method described by Pellow (Pellow and File, 1986) and similarly as in our previous study (Wierońska et al, 2003). Briefly, the plus-maze apparatus was made of wood and consisted of two open arms, $50 \times 10 \mathrm{~cm}$, and two closed arms, $50 \times 10 \times 40 \mathrm{~cm}$, and an open roof. It was painted black but the wooden walls of the closed arms maintained their natural color. The apparatus was elevated $50 \mathrm{~cm}$ above the floor. Two open arms were opposite to each other and were illuminated with a $40 \mathrm{~W}$ bulb positioned $20 \mathrm{~cm}$ above each of them.

The design of experiment is presented in Table 1.

NPY and mGluR ligands were given $20 \mathrm{~min}$ before the plus-maze test, whereas BIBO 3304 or BIIE 0246 was injected $10 \mathrm{~min}$ before those drugs. The doses and administration schedule were established in accordance with some earlier studies and our preliminary experiments (Shigemoto et al, 1997; Tatarczynska et al, 2001; Wierońska et al, 2005; Śmiałowska et al, 1996, 2002; Heilig et al, 1993).

Each rat was placed individually in the experimental room for habituation for $5 \mathrm{~min}$ immediately before the test (that procedure resulted in an increase in the total number of arm entries during the test). Each rat was then placed in the center of the plus-maze facing one of the open arms. During a 5-min test, the number of entries into the open arms and the time spent in those arms were measured and the results were calculated as a percentage of time and 
Table I Groups of Rats Used in Experiments

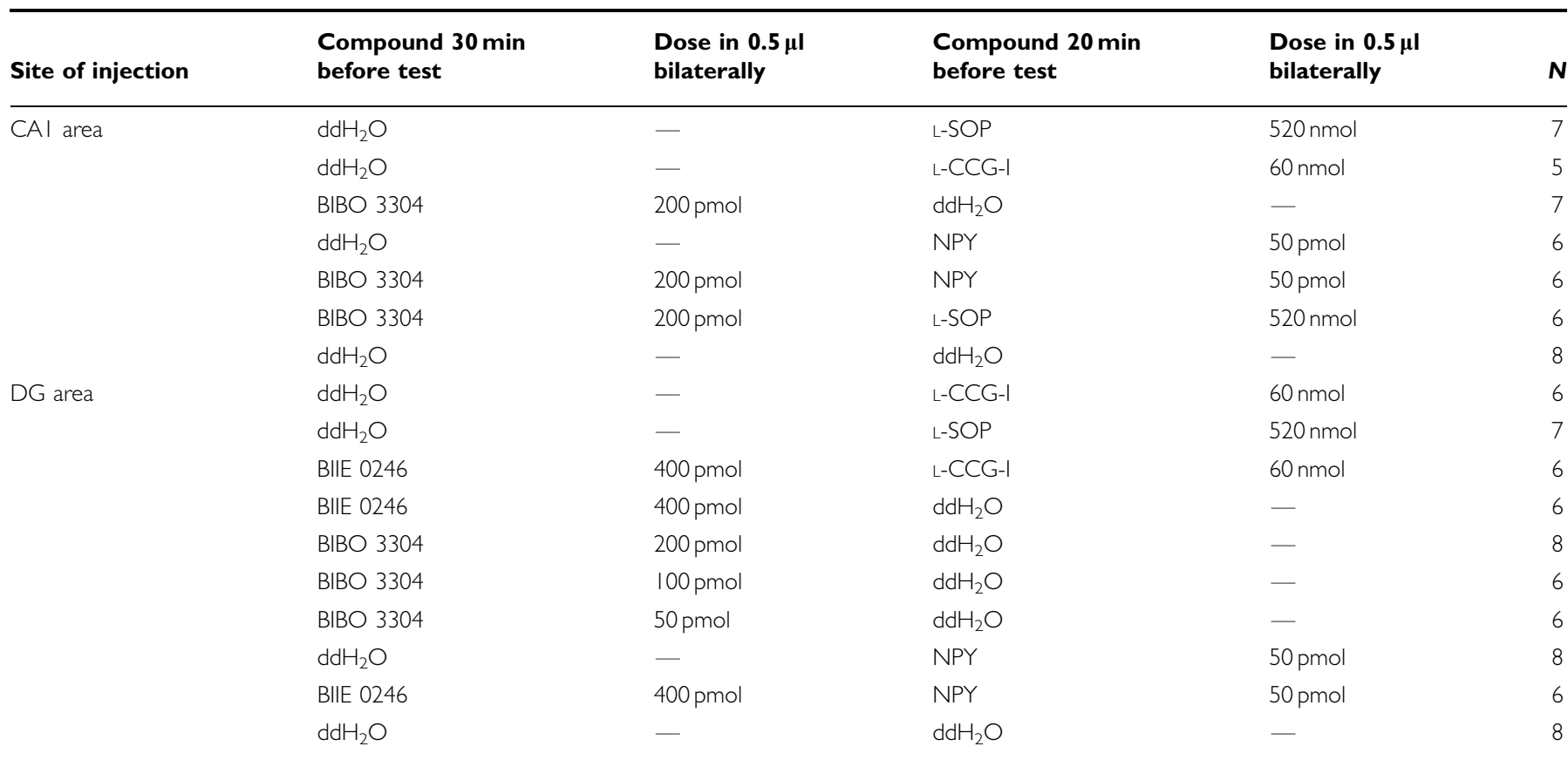

The compounds were microinjected bilaterally, each dose in a volume of $0.5 \mu$ l. Control animals received the same volume of redistilled water for injection (ddH $\mathrm{O}_{2}$ ). $N=$ number of animals.

entries into the open arms. The maze was cleaned with a paper towel after each trial. The experiments were performed between 0900 and 1200 hours.

\section{NPYmRNA In Situ Hybridization}

L-CCG-I was injected into the DG (seven rats), or L-SOP into the CA1 (four rats). Control rats received distilled water into the DG or CA1 (the whole group consisted of seven rats). Twenty-four hours after the injection the animals were decapitated. Their brains were taken out, frozen in isopentane at $-70^{\circ} \mathrm{C}$, and were then cut on a cryostat into $20 \mu \mathrm{m}$ frontal sections containing the dorsal hippocampus at levels ranging from -2.30 to $-3.80 \mathrm{~mm}$ with respect to bregma, according to the Paxinos and Watson atlas (Paxinos and Watson, 1986). The sections were thaw mounted on chrome-alum-gelatine-coated microscopic slides and stored at -20 to $80^{\circ} \mathrm{C}$ until in situ hybridization. The sections were then fixed in a $4 \%$ paraformaldehyde for $10 \mathrm{~min}$ and processed for in situ hybridization according to Young et al (1986), as described previously (Śmiałowska et al, 1999), and were hybridized with an NPY oligonucleotide probe $\left(1 \times 10^{6}\right.$ c.p.m. $\left./ 100 \mu \mathrm{l}\right)$ for $18 \mathrm{~h}$ at $42^{\circ} \mathrm{C}$ in a humidified incubator. A 44 base synthetic deoxynucleotide (Genset-Oligo) with the sequence 5'TTGATGTAGTGT CGCAGAGCGGAGTAGTATCTGGCCATGTCCTC3' of rat NPYmRNA was used. The probe was labelled using dATP, $1250 \mathrm{Ci} / \mathrm{mmol}$ (ICN), to obtain specific activity of about $2 \times 10^{6} \mathrm{Ci} / \mathrm{mol}$ (Terminal Transferase (TdT, Roche) was used for this reaction). The specificity of the probe was confirmed by competition hybridization experiments with high molar excess of unlabelled antisense mRNA probe added to the prehybridization solution together with ${ }^{35} \mathrm{~S}$ labelled probe. After hybridization, washings were per- formed according to following procedure: $5 \mathrm{~s}$ in $1 \times \mathrm{SSC}$ buffer in RT, three times $15 \mathrm{~min}$ in $1 \times \mathrm{SSC}$ in $55^{\circ} \mathrm{C}$ and 30 min $1 \times$ SSC in RT. The sections were than exposed to a Kodak BioMax MR film for 4 weeks. Then the X-ray films were developed in a Kodak Rapidfix and dried. The quantification of signals was carried out on the films in regions corresponding to the hippocampi in brain sections using MCID software. Quantitative changes in the hybridization signals were recorded as relative optical density (ROD) units after subtraction of the film background density. The ROD was measured in two regions of the hippocampal formation, CA (which contained CA1 to CA3) and DG (containing all DG layers, hilus and CA4), as shown in Figure 4. Measurements were performed on at least eight sections for each rat, and were then expressed as a mean value for each group. A statistical analysis was carried out using one-way ANOVA followed by the Newman-Keuls test. After the films were removed, the slides with the sections were dipped in a photosensitive emulsion (Amersham) at $42^{\circ} \mathrm{C}$, dried, and left in the darkness at $4^{\circ} \mathrm{C}$ for 6 weeks. The sections covered with the emulsion were developed in a Kodak Rapidfix, lightly counterstained with cresyl violet, dehydrated, cleared, cover-slipped with a Canada balsam and analyzed under a light microscope. The grain density on emulsion-dipped sections were only observed and photographed but not quantified. Quantification was performed only in the X-ray films. The microscopic observations were performed additionally and allowed us to see the grains on individual neurons (lightly stained with cresyl violet). Location of the grain-positive neurons (mainly in the hilus) and their morphology resembled NPY-immunoreactive neurons often observed by us in previous immunohistochemical studies and also described by other authors. Therefore, our microscopic observations 
confirmed both specificity of the in situ method and increase in NPYmRNA expression in some nerve cell bodies. The NPY mRNA-positive neurons were not counted, but we observed that the grains over individual neurons were more numerous in treated rats.

\section{RESULTS}

\section{Behavioral Studies: Plus-Maze Test}

Effects of $L-S O P, L-C C G-I$, and NPY injected into the CA1. L-SOP (mGluR III agonist) microinjected into the CA1 area induced an anxiolytic-like effect, that is, it significantly increased the percentage of open arm entries (from $29 \%$ in controls to $46 \%$ in L-SOP-treated rats) and the percentage of the time spent in the open arms (from $12 \%$ in controls to $33 \%$ in L-SOP-treated animals). This anxiolytic effect was significantly prevented by the Y1 receptor antagonist BIBO 3304 given at a dose of $200 \mathrm{pmol} / 0.5 \mu \mathrm{l} / \mathrm{site}$ (Figure 1). BIBO 3304 alone did not affect the number of entries or the time spent in the open arms of the maze. Similar anxiolytic effect was also observed after NPY injection into the CA1; this effect was also inhibited by BIBO 3304 (Figure 1). L-CCG-I injection into the CA1 did not affect the anxiety of rats. The number of entries and time spent in the open arms remained at the control level (Figure 1).

Effects of L-CCG-I, L-SOP, and NPY injected into the DG. L-CCG-I evoked an anxiolytic-like effect after the administration into the DG. The percentage of the time spent in the open arms increased significantly from $9 \%$ in controls to $19 \%$ in L-CCG-I-treated rats. The increase was prevented by BIIE 0246 at a dose of $400 \mathrm{pmol} / 0.5 \mu \mathrm{l} / \mathrm{site}$ (Figure 2). The percentage of the number of open arms entries showed only an insignificant tendency to the increase after L-CCG-I injection into the DG. No significant influence on anxiety was found after L-SOP injection into the DG.

NPY administration into the DG $(50 \mathrm{pmol} / 0.5 \mu \mathrm{l} / \mathrm{site})$ induced a potent anxiolytic effect in the plus-maze test. Both the time spent in the open arms and the number of open arms entries significantly increased (from 9 to $36 \%$ and from 32 to $58 \%$, respectively). Those increases were prevented by BIIE $0246,400 \mathrm{pmol} / 0.5 \mu \mathrm{l} /$ site (Figure 2). BIIE 0246 alone given at the same dose into the DG did not change behavioral parameters assessed in the plus-maze test.

The time spent in the open arms and the number of open arm entries were significantly increased after injection of BIBO 3304 into the DG $(200,100$, or $50 \mathrm{pmol} / 0.5 \mu \mathrm{l} / \mathrm{site})$ (Figure 3); therefore, that compound was not used for preventing anxiolysis in further studies in the DG.

\section{NPYmRNA In Situ Hybridization}

Grain density was measured separately in the CA regions (CA1-CA3) and the DG areas (Figure 4). Such evaluation showed that ROD increased in the DG but not in the CA (Figure 5). The increase was highly significant after L-CCG-I injection into the DG. A strong but nonsignificant increase was observed after L-SOP microinjection into the CA1. Microscopic observations of the sections covered with emulsion showed clearly visible increases in the number of
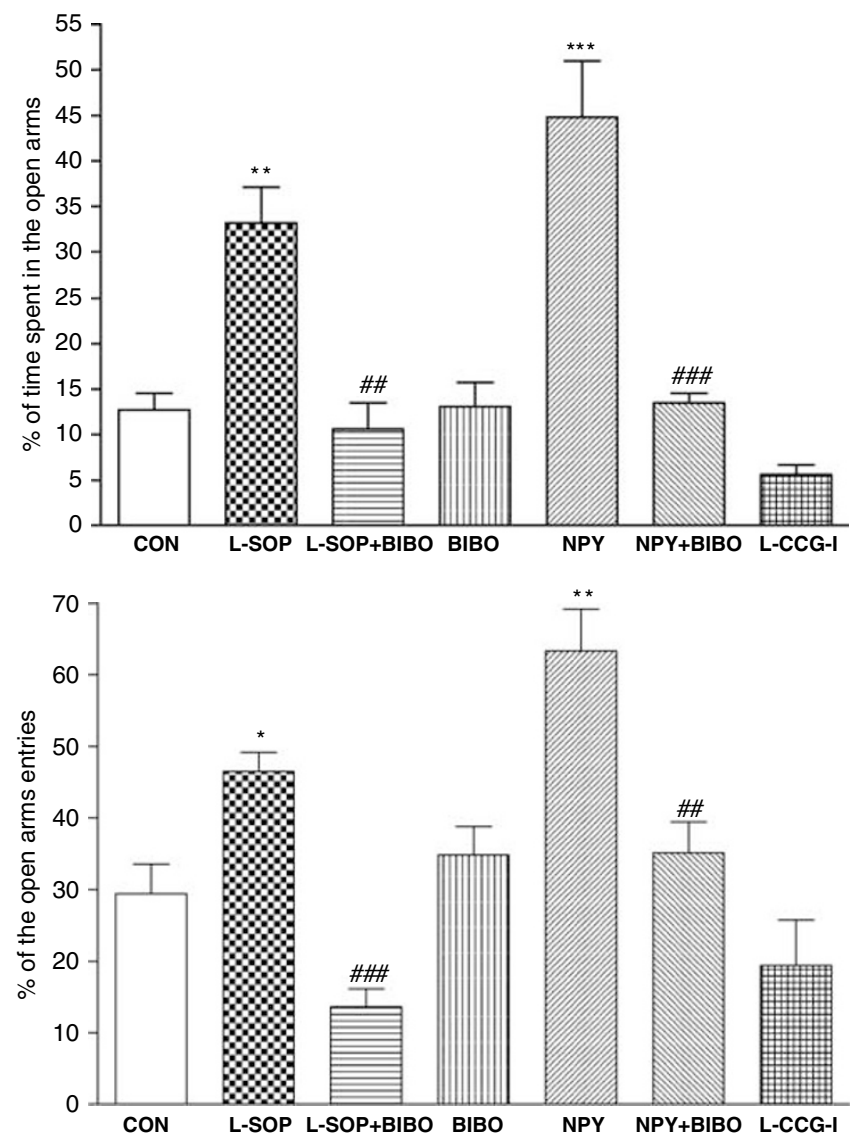

Figure I Measurements of anxiolytic-like effects in the plus-maze test, after bilateral microinjectios into the CAI area of rat hippocampus. The significant antianxiety action was found after L-SOP $(520 \mathrm{nmol} / 0.5 \mu \mathrm{l} / \mathrm{side})$ and NPY $(50 \mathrm{nmol} / 0.5 \mu \mathrm{l} / \mathrm{side})$. The effects were prevented by BIBO 3304 (200 pmol/0.5 $\mu \mathrm{l} / \mathrm{side})$. BIBO 3304 alone and L-CCG-I $(60 \mathrm{nmol} / 0.5 \mu \mathrm{l} / \mathrm{side})$ had no effect. (CON = control rats). NPY and mGluR ligands were injected 20 min before the test, whereas BIBO 3304 was given 10 min before those drugs. $N=$ at least six rats per group. Statistical significance was calculated using two-way ANOVA, and Newman-Keuls for post hoc comparison. The time spent in the open arms: L-SOP, $\mathrm{F}(\mathrm{I} .29)=9.73$, ${ }^{*} *$ $p<0.00$ I vs control; L-SOP + BIBO 3304, F(I.29) = I0.53, ${ }^{\# \# p<0.001}$ vs L-SOP; NPY, F $(I .31)=23.57$, $* * * * 0<0.0001$ vs control; NPY + BIBO

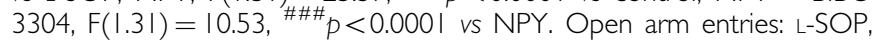
$F(\mid .28)=12.2, * p<0.01$ vs control; L-SOP + BIBO 3304, $F(\mid .28)=18.93$, $\# \#$ \#\# $<0.000$ I vS L-SOP; NPY, $F(I .30)=5.78$, *** $p<0.00$ I vs control; $\mathrm{NPY}+\mathrm{BIBO} 3304, \mathrm{~F}(1.30)=13.13,{ }_{p}{ }_{p}<0.001$ vs NPY.

labelled neurons and in the grain density over individual neurons, mainly in the hilar region of the DG, after the administration of either compound (Figure 6).

\section{DISCUSSION}

Our present results show that two mGluR agonists, L-CCG-I and L-SOP, may induce anxiolytic effects in rats after intrahippocampal injection. However, these effects depend on the region of the hippocampal formation. L-SOP, a group III mGluR agonist, displayed anxiolytic activity after injection into the CA1 area, but not into the DG. On the other hand, L-CCG-I, a group II mGluR agonist, was active after microinjection into the DG but not CA1. The above 

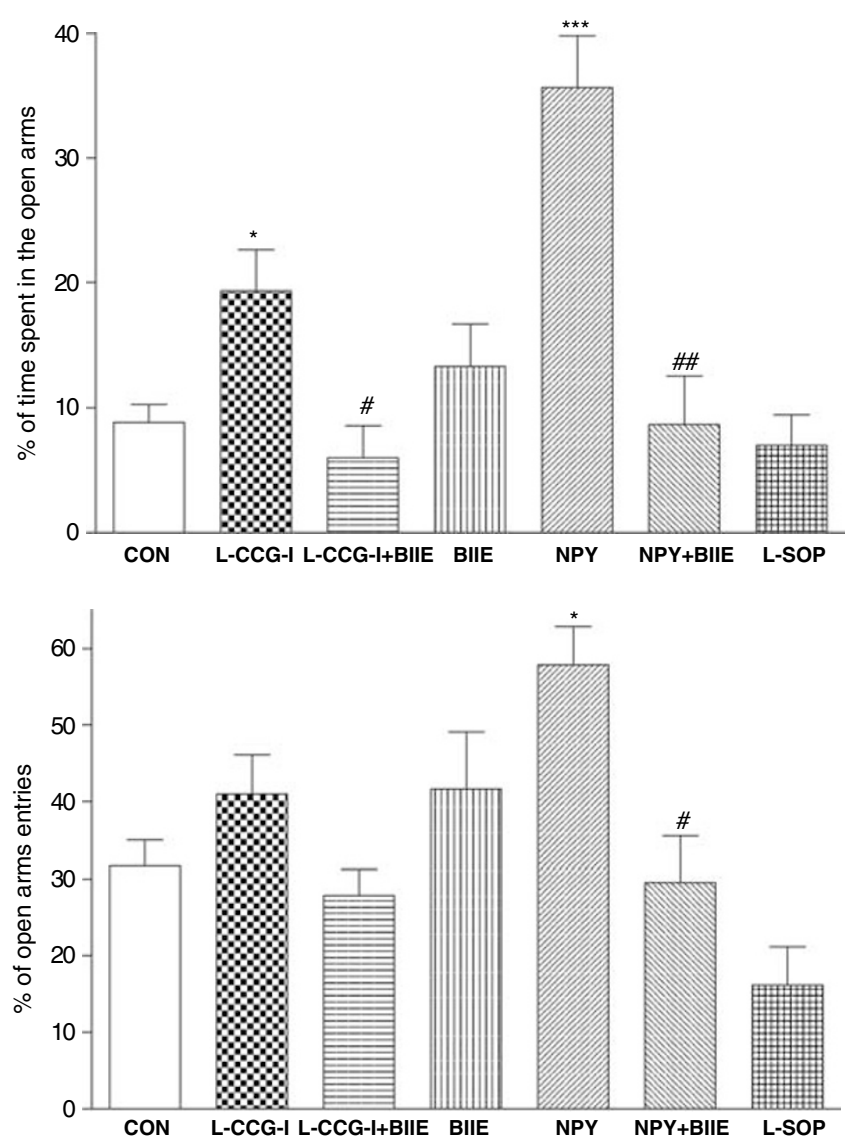

Figure 2 Measurements of anxiolytic-like effects in the plus-maze test after bilateral microinjectios into the DG region of rat hippocampus. The antianxiety action was evidenced after L-CCG-I $(60 \mathrm{nmol} / 0.5 \mu \mathrm{l} / \mathrm{side})$ and $\mathrm{NPY}(50 \mathrm{nmol} / 0.5 \mu / \mathrm{side})$. The effects were prevented by BIIE 0246 (400 pmol/ $0.5 \mu \mathrm{l} / \mathrm{side}$ ). BIIE 0246 alone and L-SOP ( $520 \mathrm{nmol} / 0.5 \mu \mathrm{l} / \mathrm{side})$ had no significant effect. (CON = control rats). NPY and mGluR ligands were injected 20 min before the test, whereas BIIE 0246 was given 10 min before those drugs. $N=$ at least six rats per group. Statistical significance was calculated using two-way ANOVA, and Newman-Keuls for post hoc comparison. The time spent in the open arms: L-CCG-I, $F(\mid .20)=10.22$, $* p<0.05$ vs control; L-CCG-I +BIIE, $F(I .20)=10.22, \quad \# p<0.01$ vs L-CCG-I; NPY, $F(I .26)=10.35$, **** $<<0.000$ I vs control; NPY + BIIE, $F(1.26)=20.9,{ }^{\# \#} p<0.001$ vs NPY. Open arm entries: there were no significant effects in this parameter for L-CCG-I and BIIE, effect of NPY was significant, $F(I .26)=9.7$, $* p<0.05$ vs control; NPY + BIIE, $F(I .26)=9.7$, $\#_{p}<0.01$ vs NPY

results may be partly due to differences in the distribution of certain mGluRs in the hippocampus. Using immunohistochemical method, it was demonstrated that in the rat hippocampus, mGluRs 2/3 (which belong to group II mGluRs) were situated mainly in the DG region and in the stratum lacunosum-moleculare of the CA on the border with the DG. On the other hand, the CA1 area was rich in mGlu7a receptors which belong to group III mGluRs (the other receptors of group III: mGlu7b, mGlu4a, mGlu6, and mGlu8 were visibly less dense or even hardly detectable) (Shigemoto et al, 1997). Therefore, the anxiolytic effect or its lack seems to be due to the presence of the appropriate receptors in the structure: mGluR7 for L-SOP and mGluR2/3 for L-CCG-I. Earlier studies with different mGluR ligands (Tatarczynska et al, 2001) showed that both L-CCG-I and L-SOP exhibited antianxiety-like effects after injection
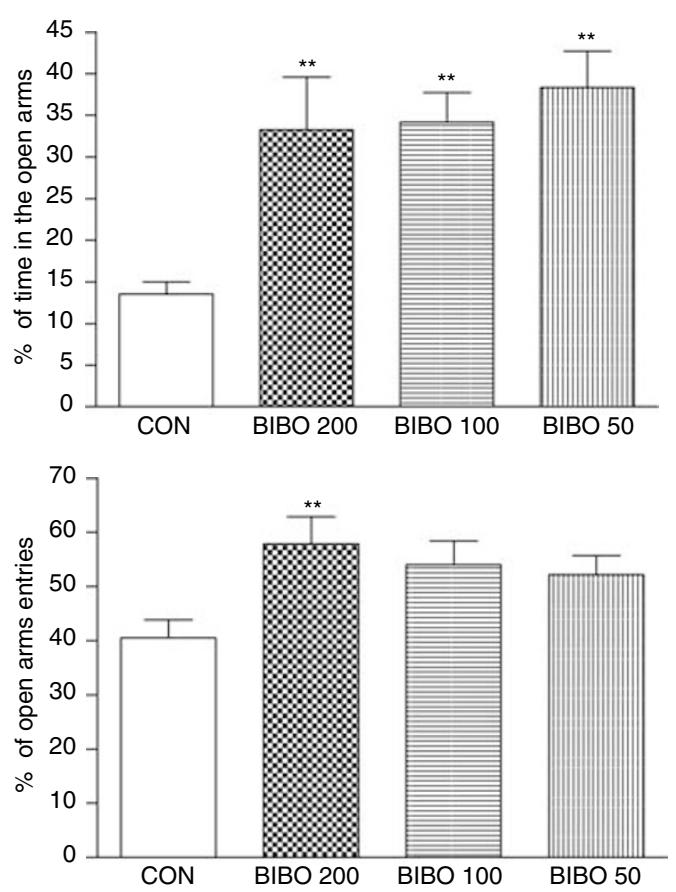

Figure 3 Measurements of anxiolytic-like effects of BIBO 3304 in the plus-maze test, after bilateral microinjectios into the DG region of rat hippocampus. The antianxiety action was observed at all tested doses. Statistical significance was calculated using one-way ANOVA and Newman-Keuls for post hoc comparison. $F(3,24)=6.53$, *** $<0.01$. $N=$ at least six rats per group.

into the CA1 hippocampal area. The discrepancy between those and our present results may result from differences in the volume of injections and the test used. We injected the compounds in a volume of $0.5 \mu \mathrm{l}$ on each side, but the latter authors used a volume of $1 \mu \mathrm{l}$. It may be possible that when a greater volume is injected into the CA1, the compound partly diffuses into the DG. Moreover, the above-cited authors used the Vogel conflict test, whereas we applied the plus-maze test, so different mechanisms of anxiety might have been engaged.

Our previous studies (Wierońska et al, 2003, 2005) indicated that the anxiolytic effects of mGluR ligands, injected systemically or into the basolateral amygdala were mediated by NPY neurons in the amygdala and involved Y1 receptors. Our present behavioral studies revealed that the anxiolytic effects in the plus-maze of both L-SOP and LCCG-I after intrahippocampal injection were also connected with the activation of NPY transmission, as those effects were blocked by NPY receptor antagonists. Interestingly, the effects were different in the CA1 and the DG. In the CA1 region, the anxiolytic action of L-SOP (an agonist of group III mGluRs) was prevented by BIBO 3304, a specific Y1 receptor blocker; on the other hand, the antianxiety action of $\mathrm{L}-\mathrm{CCG}-\mathrm{I}$ in the DG was prevented by BIIE 0246, a specific Y2 receptor antagonist. Moreover, in the DG, the blockade of Y1 receptors by BIBO 3304 alone induced a significant antianxiety action. Therefore, it can be hypothesized that in the CA1, Y1 receptors are engaged in the anxiolytic effect of L-SOP, whereas in the DG Y2 (but not Y1) receptors are necessary for the development of antianxiety effect observed after L-CCG-I. 

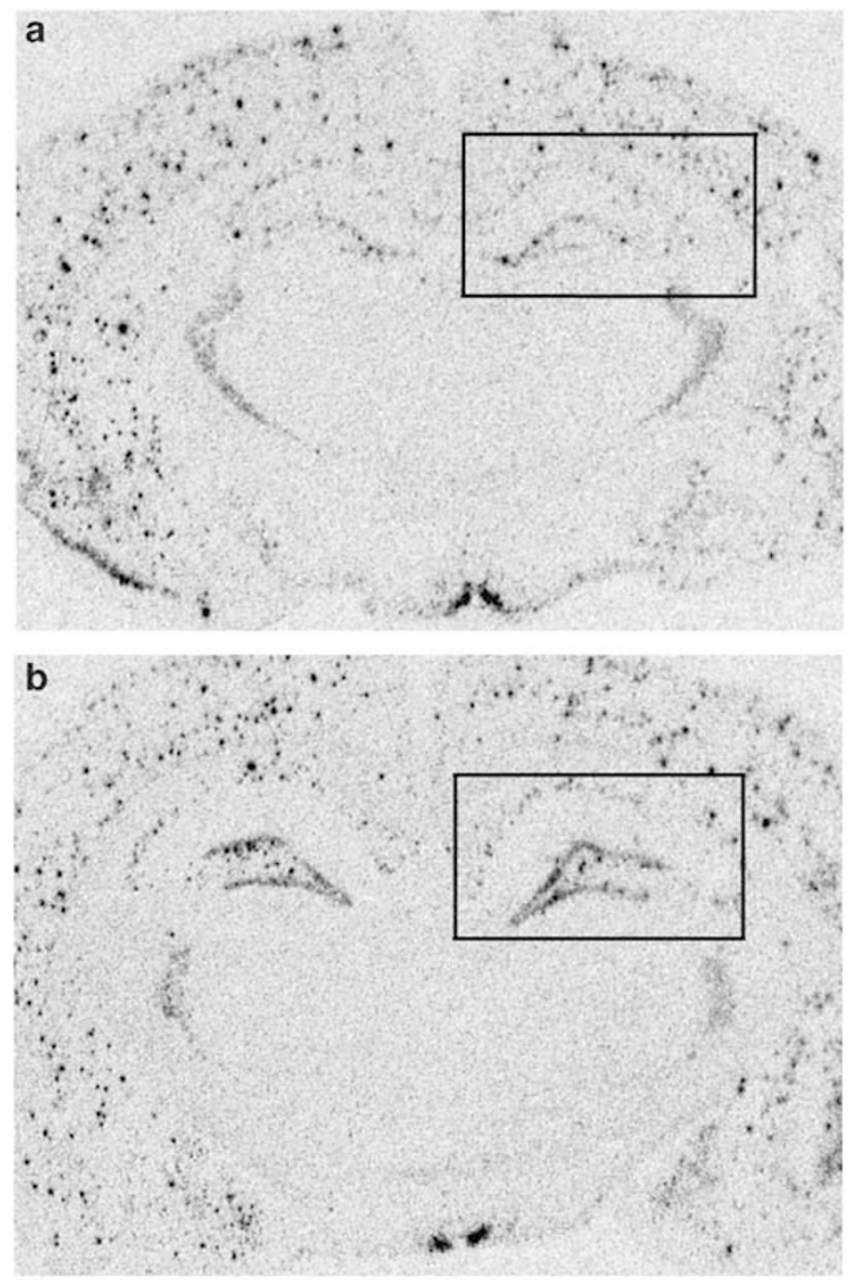

C

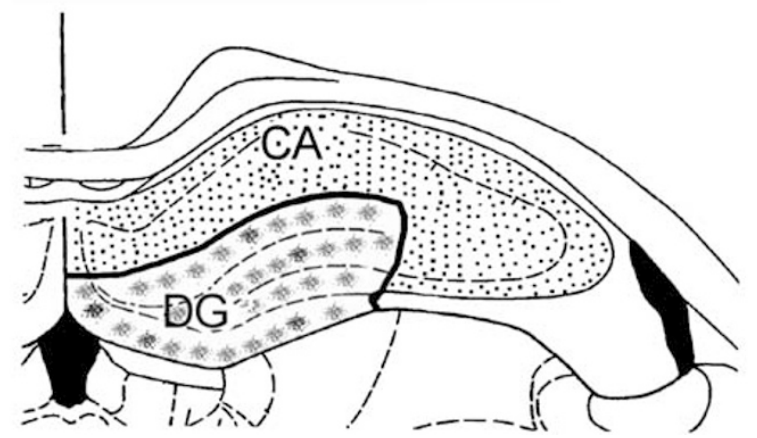

Figure 4 (a) and (b) - in situ hybridization autoradiography of NPYmRNA in film autoradiograms from the coronal sections of the rat brain, at levels about $-2.80 \mathrm{~mm}$ from bregma (according to the Paxinos and Watson stereotaxic atlas (1986) taken from the control (a), and L-SOP (b)-treated rat. (c) - Schematic drawing of the hippocampus contained in the fragments of sections framed in $(a, b)$. Scheme shows the hippocampal regions, CA and DG, where optical density analysis was conducted.

The role of NPY, as a mediator in the anxiolytic activity of mGluR ligands in the hippocampus has been confirmed by our results obtained after NPY microinjections. To date, there have been no studies concerning the anxiolytic action of NPY after intrahippocampal injection. The antianxiety function of NPY in the hippocampus has been postulated on the basis of the results obtained in transgenic mice with hippocampal NPY overexpression (Thorsell et al, 2000).
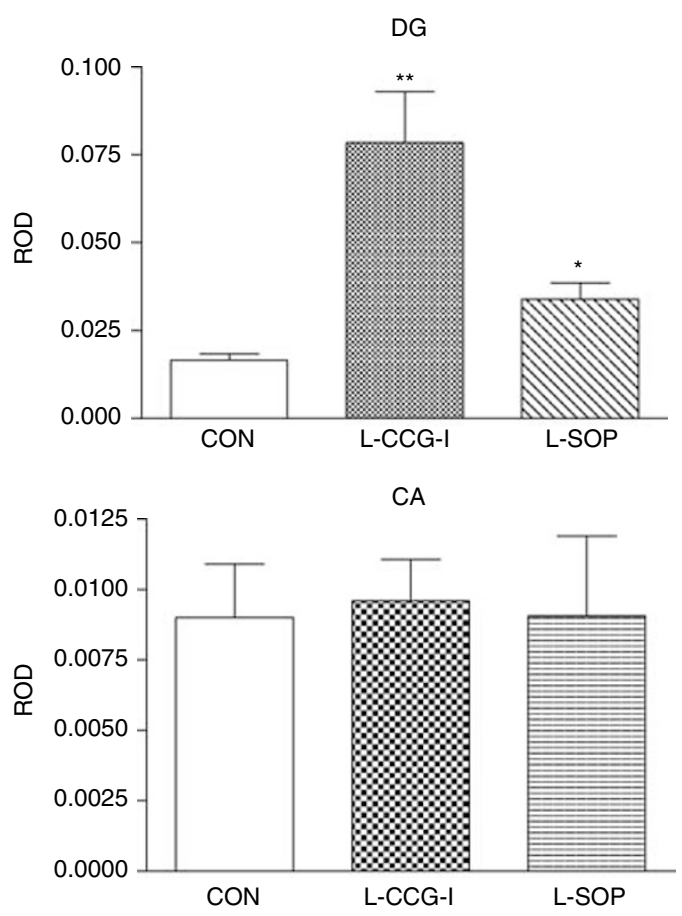

Figure 5 The effect of L-CCG-I $(60 \mathrm{nmol} / 0.5 \mu / \mathrm{side})$ and L-SOP $(520 \mathrm{nmol} / 0.5 \mu /$ side) microinjections into the DG or CAI, respectively, on NPYmRNA expression in hippocampal regions DG and CA $24 \mathrm{~h}$ after the injections. Each column represents the mean ROD per section. The significant increase in NPYmRNA expression was observed in DG but not in CA. The statistical significance was calculated by one-way ANOVA followed by Newman-Keuls for post hoc comparison. $F(2.14)=9.96 . \mathrm{N}=7$ (Control and L-CCG-I) to 4 (L-SOP). ${ }^{*} p<0.0 \mathrm{I}$ and ${ }^{* *} p<0.001$.

Our results revealed that NPY, injected into either the CA1 or the DG region, induced anxiolytic effects, which were prevented by the blockade of Y1 and Y2 receptors, respectively. Autoradiographic binding studies and in situ hybridization have shown that $\mathrm{Y} 1$ and $\mathrm{Y} 2$ receptors are quite abundant in the rat hippocampus (Dumont et al, 1990, 1992; McQuiston et al, 1996; Wahlestedt and Reis, 1993; McQuiston et al, 1996). According to some earlier results obtained by our group and by other authors (Sajdyk et al, 1999; Wierońska et al, 2004, 2005), NPY shows anxiolytic activity in the amygdala, and this effect is mediated by Y1 receptors, as it is blocked by BIBO 3304. Moreover, Y2 receptors have been suggested to have an opposite, anxiogenic function (Nakajima et al, 1998; Sajdyk et al, 2002; Tschenett et al, 2003). Our present study indicates that in the hippocampus both Y1 and Y2 receptors seem to be implicated in the antianxiety effect of NPY, but differently in CA1 and DG. Our results showed that whereas Y1 receptor antagonist BIBO 3304 prevented the anxiolytic action of both L-SOP and NPY in the CA1 region, it induced antianxiety effects itself after injection into the DG. Therefore, it seems that regulation of anxiety by NPY in DG area is opposite to that in CA1. Although the anxiolytic action of NPY in CA1 seems to be mediated by Y1 receptors, similarly as in the amygdala, a reverse role of the $\mathrm{Y} 1$ receptors is found in DG. Therefore, the hypofuction of $\mathrm{Y} 1$ in comparison to Y2 (or maybe also other $\mathrm{Y}$ receptors) produces the anxiolysis. 

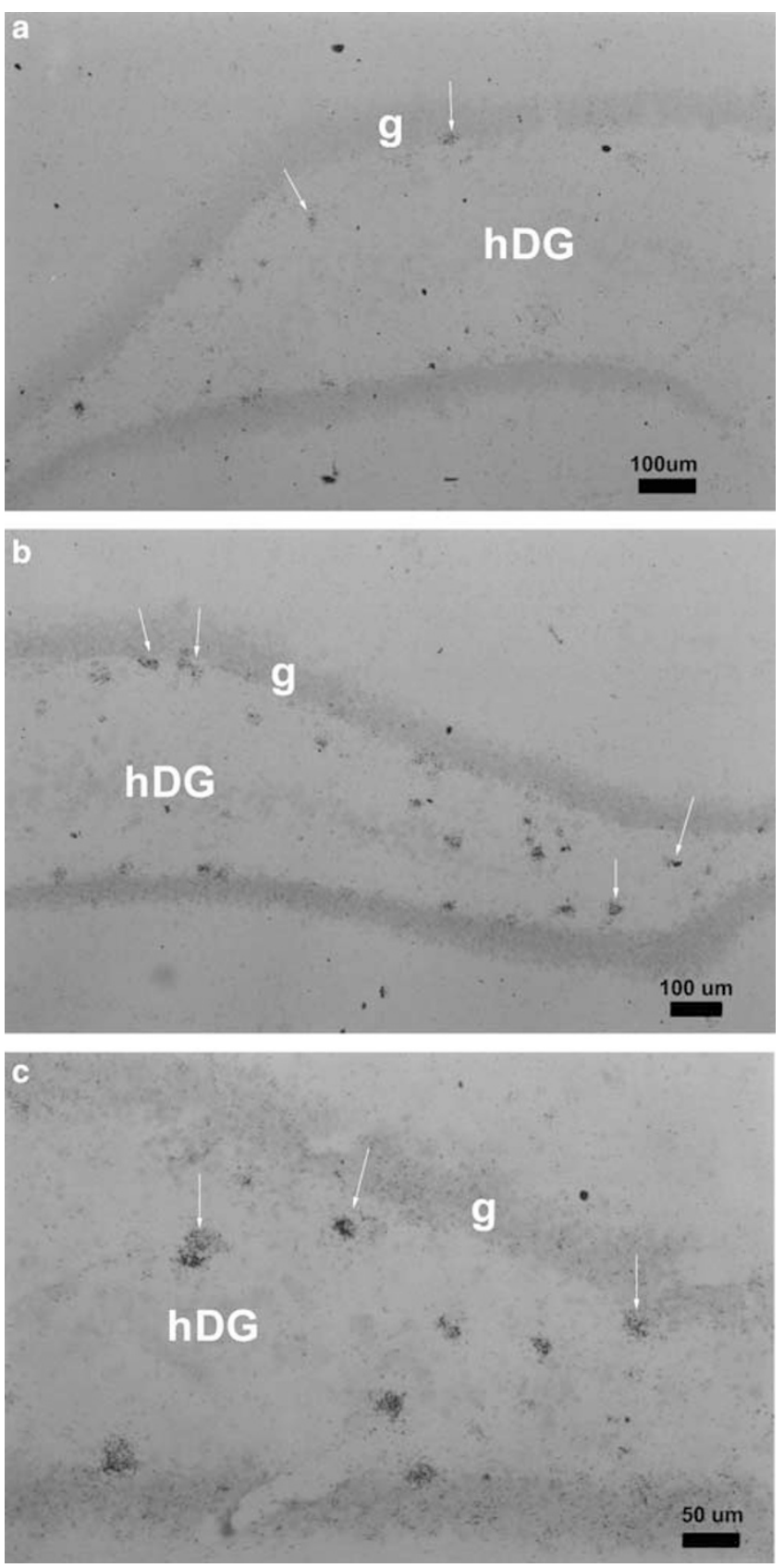

Figure 6 Photomicrographs showing NPYmRNA expression in emulsion-covered coronal sections from the region of dentate gyrus (DG) of the rat hippocampal formation. An increase in a number of labelled neurons and in grain density over individual neurons is seen after L-SOP (b) and LCCG-I (c) microinjection in comparison with the control (a). Some labelled neurons are marked. hDG-hilus of the dentate gyrus, g-granular layer of DG.

Anxiolytic effects of group II and III mGluR agonists were reported previously by some authors (Yoshimizu et al, 2006; Linden et al, 2005; Shimazaki et al, 2004; Tizzano et al, 2002) and by our group (Palucha et al, 2004; Tatarczynska et al, 2002). More detailed studies were performed with group III agonists, using Vogel drinking test for studying anxiolysis. It was found that the effects of various ligands of distinct receptors depended on the injection site, for example, hippocampus or amygdala (Professor A Pilc, personal communication). Therefore, the divergent mechanisms of anxiolysis found in the present studies between CA1 and DG seems to be in line with these previous findings.

The results of our in situ hybridization studies after L-SOP and L-CCG-I microinjections point to the DG as a structure engaged in the effect of both these compounds on the mechanism of NPY action in the hippocampus, as, irrespective of the injection site (CA1 or DG), an increase in NPYmRNA expression is observed in the DG. On the basis of previous studies (Wierońska et al, 2004, 2005; Kłodzińska et al, 2004; Ferris et al, 2001), an implication of interneurons in the anxiolytic effects of mGluR ligands has been postulated. Many interneurons in the hippocampus contain NPY as a neurotransmitter/neuromodulator and such NPY neurons are especially numerous in the hilar region of DG (de Quidt and Emson, 1986). Our findings demonstrate that the stimulation of NPYmRNA expression by the studied compounds is the most visible in the DG. Statistical analysis of ROD measurements on the autoradiographic films demonstrated the significant increase in the grain density in DG region after L-CCG-I only, but not after L-SOP treatment, when we used ANOVA analysis followed by Newman-Keuls test (it attained significance in the Student's $t$-test). On the other hand, detailed analysis of sections covered with autoradiographic emulsion clearly visualized the increase in grain density above the individual neurons, moreover, such neurons were more numerous (Figure 6). Our previous RIA studies in the hippocampus showed a significant increase in NPY level after both L-CCG-I and L-SOP administration (Śmiałowska et al, 2002). Therefore, we may generally assume that both compounds stimulate hippocampal NPY neurons, especially in the DG hilar region.

It is not clear how the effect of the injection into CA1 may be transmitted to DG area, but back-projection inhibitory interneurons have been found in the CA1. Their axons form large arbors in the CA3 and in the hilar region of the DG (Sik et al, 1994, 1995; Freund and Buzsaki, 1996). An engagement of longer multisegmental pathways and astroglial cells seems to be also possible.

Behavioral studies conducted by many authors have shown that the increase in glutamatergic activity leads to anxiety; conversely, inhibition of this transmission produces antianxiety effects (Chojnacka-Wójcik et al, 2001; Pilc et al, 2000; Tatarczynska et al, 2001; Helton et al, 1998; Monn et al, 1997; Dunn et al, 1989). L-SOP and L-CCG-I are agonists of group III mGluRs and it is generally accepted that the activation of these receptors results, via a presynaptic mechanisms, in a modulatory inhibition of Glu transmission (Gereau and Conn, 1995; Vignes et al, 1995). Therefore, the antianxiety action of both these compounds is in line with the above-mentioned concept about the role of Glu transmission in anxiety. On the other hand, studies of the interdependence of glutamate and NPY in the hippocampus have shown that glutamatergic activation increases the synthesis and expression of NPY in hippocampal neurons (Schwarzer and Sperk, 1998; Schwarzer et al, 1996; Marksteiner et al, 1990; Bellmann et al, 1991; Bendotti et al, 1991) and that NPY inhibits Glu transmission in this structure (Silva et al, 2005; Tu et al, 2005; Klapstein and Colmers, 1997; Bijak and Śmiałowska, 1995; 
Śmiałowska et al, 1996; Vezzani et al, 1999). Thus, the increase in NPY mRNA observed in our study after L-SOP and L-CCG-I seems to be the consequence of the enhanced activation of NPY neurons by Glu. To explain these discrepancies, we hypothesize that the net effect of the ligands under study entails the stimulation of NPY interneurons, especially in the DG. Group II and III mGluRs are localized mainly presynaptically and they inhibit the release of transmitters from terminals; however, they may regulate not only Glu terminals, but also other terminals. Electron microscopy studies on the localization of mGluRs in the hippocampus have demonstrated that they are located on preterminals and terminals of axons, which form asymmetrical (excitatory) and symmetrical (inhibitory) synapses with dendrites of both primary excitatory neurons and interneurons (Shigemoto et al, 1997). Thus, the activation of mGluRs by L-SOP and L-CCG-I may involve a complex network of neuronal connections in which the inhibition of inhibitory interneurons may lead to stimulation. The above-mentioned net stimulatory effect of the ligands under study triggers the production and release of NPY, which acts anxiolytically via Y1 and Y2 receptors. The NPY neurons may be activated indirectly through interneurons and possibly also glial cells.

Summing up, our results demonstrate the anxiolytic effects of a group III mGluRs agonist L-SOP and group II mGluRs agonist L-CCG-I after intrahippocampal injection into the CA1 and DG, respectively. These effects are conveyed by the activation of NPY neurons, with the involvement of $\mathrm{Y} 1$ receptors in the $\mathrm{CA}$ region and $\mathrm{Y} 2$ receptors in the DG. Furthermore, our previous and present results indicate that mGluR ligands may constitute in the future a new class of anxiolytic drugs acting through NPY mechanisms.

\section{ACKNOWLEDGEMENTS}

The study was supported by statutory founds of the Institute of Pharmacology, Polish Academy of Sciences, Kraków, Poland.

\section{REFERENCES}

Bellmann R, Widmann R, Olenik C, Meyer DK, Maas D, Marksteiner J et al (1991). Enhanced rate of expression and biosynthesis of neuropeptide $\mathrm{Y}$ after kainic acid-induced seizures. J Neurochem 56: 525-530.

Bendotti C, Vezzani A, Serafini R, Servadio A, Rivolta R, Samanin $R$ (1991). Increased preproneuropeptide $Y$ mRNA in the rat hippocampus during the development of hippocampal kindling: comparison with the expression of preprosomatostatin mRNA. Neurosci Lett 132: 175-178.

Bijak M, Śmiałowska M (1995). Effects of neuropeptide Y on evoked potentials in the CA1 region and the dentate gyrus of the rat hippocampal slice. Pol J Pharmacol 47: 333-338.

Chojnacka-Wójcik E, Kłodzińska A, Pilc A (2001). Glutamate receptor ligands as anxiolytics. Curr Opin Investig Drugs 2: 1112-1119.

Chojnacka-Wójcik E, Tatarczynska E, Pilc A (1997). The anxiolytic-like effect of metabotropic glutamate receptor antagonists after intrahippocampal injection in rats. Eur J Pharmacol 319: $153-156$. de Quidt ME, Emson PC (1986). Distribution of neuropeptide Y-like immunoreactivity in the rat central nervous system-II. Immunohistochemical analysis. Neuroscience 18: 545-618.

Dumont Y, Fournier A, St Pierre S, Schwartz TW, Quirion R (1990). Differential distribution of neuropeptide Y1 and Y2 receptors in the rat brain. Eur J Pharmacol 191: 501-503.

Dumont Y, Jacques D, Bouchard P, Quirion R (1998). Species differences in the expression and distribution of the neuropeptide Y Y1, Y2, Y4, and Y5 receptors in rodents, guinea pig, and primates brains. J Comp Neurol 402: 372-384.

Dumont Y, Martel JC, Fournier A, St Pierre S, Quirion R (1992). Neuropeptide $\mathrm{Y}$ and neuropeptide $\mathrm{Y}$ receptor subtypes in brain and peripheral tissues. Prog Neurobiol 38: 125-167.

Dunn RW, Corbett R, Fielding S (1989). Effects of 5-HT1A receptor agonists and NMDA receptor antagonists in the social interaction test and the elevated plus maze. Eur J Pharmacol 169: 1-10.

Eichenbaum H, Otto T, Cohen NJ (1992). The hippocampus - what does it do? Behav Neural Biol 57: 2-36.

Ferris P, Seward E, Dawson GR (2001). Interactions between LY354740, a group II metabotropic agonist and the GABA(A)benzodiazepine receptor complex in the rat elevated plus-maze. J Psychopharmacol 15: 76-82.

Freund TF, Buzsaki G (1996). Interneurons of the hippocampus. Hippocampus 6: 347-470.

Gereau RW, Conn PJ (1995). Multiple presynaptic metabotropic glutamate receptors modulate excitatory and inhibitory synaptic transmission in hippocampal area CA1. J Neurosci 15: 6879-6889.

Gray JA (1982). Precis of the neuropsychology of anxiety: an enquiry into the functions of the septo-hippocampal system. Behav Brain Sci 5: 469-534.

Heilig M, McLeod S, Brot M, Heinrichs SC, Menzaghi F, Koob GF et al (1993). Anxiolytic-like action of neuropeptide Y: mediation by $\mathrm{Y} 1$ receptors in amygdala, and dissociation from food intake effects. Neuropsychopharmacology 8: 357-363.

Helton DR, Tizzano JP, Monn JA, Schoepp DD, Kallman MJ (1998). Anxiolytic and side-effect profile of LY354740: a potent, highly selective, orally active agonist for group II metabotropic glutamate receptors. J Pharmacol Exp Ther 284: 651-660.

Kalisch R, Schubert M, Jacob W, Kessler MS, Hemauer R, Wigger A et al (2006). Anxiety and hippocampus volume in the rat. Neuropsychopharmacology 31: 925-932.

Klapstein GJ, Colmers WF (1997). Neuropeptide Y suppresses epileptiform activity in rat hippocampus in vitro. J Neurophysiol 78: 1651-1661.

Kłodzińska A, Tatarczynska E, Chojnacka-Wójcik E, Nowak G, Cosford ND, Pilc A (2004). Anxiolytic-like effects of MTEP, a potent and selective mGlu5 receptor agonist does not involve GABA(A) signaling. Neuropharmacology 47: 342-350.

Kohler C, Eriksson L, Davies S, Chan-Palay V (1986). Neuropeptide $\mathrm{Y}$ innervation of the hippocampal region in the rat and monkey brain. J Comp Neurol 244: 384-400.

Linden AM, Shannon H, Baez M, Yu JL, Koester A, Schoepp DD (2005). Anxiolytic-like activity of the mGLU2/3 receptor agonist LY354740 in the elevated plus maze test is disrupted in metabotropic glutamate receptor 2 and 3 knock-out mice. Psychopharmacology (Berlin) 179: 284-291.

Marksteiner J, Ortler M, Bellmann R, Sperk G (1990). Neuropeptide $\mathrm{Y}$ biosynthesis is markedly induced in mossy fibers during temporal lobe epilepsy of the rat. Neurosci Lett 112: 143-148.

McQuiston AR, Petrozzino JJ, Connor JA, Colmers WF (1996). Neuropeptide $\mathrm{Y} 1$ receptors inhibit $\mathrm{N}$-type calcium currents and reduce transient calcium increases in rat dentate granule cells. J Neurosci 16: 1422-1429.

Monn JA, Valli MJ, Massey SM, Wright RA, Salhoff CR, Johnson BG et al (1997). Design, synthesis, and pharmacological characterization of (+)-2-aminobicyclo[3.1.0]hexane-2,6-dicarboxylic acid (LY354740): a potent, selective, and orally active 
group 2 metabotropic glutamate receptor agonist possessing anticonvulsant and anxiolytic properties. J Med Chem 40: 528-537.

Nakajima M, Inui A, Asakawa A, Momose K, Ueno N, Teranishi A et al (1998). Neuropeptide Y produces anxiety via Y2-type receptors. Peptides 19: 359-363.

Palucha A, Tatarczynska E, Branski P, Szewczyk B, Wierońska JM, Klak K et al (2004). Group III mGlu receptor agonists produce anxiolytic- and antidepressant-like effects after central administration in rats. Neuropharmacology 46: 151-159.

Paxinos G, Watson C (1986). The Rat Brain in Stereotaxiccoordinates, 2nd edn. Academic Press: San Diego, CA.

Pellow S, File SE (1986). Anxiolytic and anxiogenic drug effects on exploratory activity in an elevated plus-maze: a novel test of anxiety in the rat. Pharmacol Biochem Behav 24: 525-529.

Pilc A, Chojnacka-Wójcik E, Tatarczynska E, Borycz J, Kroczka B (2000). Stimulation of group II metabotropic glutamate receptors or inhibition of group I ones exerts anxiolytic-like effects in rats. Amino Acids 19: 81-86.

Pilc A, Kłodzińska A, Branski P, Nowak G, Palucha A, Szewczyk B et al (2002). Multiple MPEP administrations evoke anxiolyticand antidepressant-like effects in rats. Neuropharmacology 43: 181-187.

Pin JP, Duvoisin R (1995). The metabotropic glutamate receptors: structure and functions. Neuropharmacology 34: 1-26.

Redrobe JP, Dumont Y, St Pierre JA, Quirion R (1999). Multiple receptors for neuropeptide $\mathrm{Y}$ in the hippocampus: putative roles in seizures and cognition. Brain Res 848: 153-166.

Sajdyk TJ, Schober DA, Smiley DL, Gehlert DR (2002). Neuropeptide Y-Y2 receptors mediate anxiety in the amygdala. Pharmacol Biochem Behav 71: 419-423.

Sajdyk TJ, Vandergriff MG, Gehlert DR (1999). Amygdalar neuropeptide Y Y1 receptors mediate the anxiolytic-like actions of neuropeptide Y in the social interaction test. Eur J Pharmacol 368: 143-147.

Schwarzer C, Sperk G (1998). Glutamate-stimulated neuropeptide $Y$ mRNA expression in the rat dentate gyrus: a prominent role of metabotropic glutamate receptors. Hippocampus 8: 274-288.

Schwarzer C, Sperk G, Samanin R, Rizzi M, Gariboldi M, Vezzani A (1996). Neuropeptides-immunoreactivity and their mRNA expression in kindling: functional implications for limbic epileptogenesis. Brain Res Brain Res Rev 22: 27-50.

Shigemoto R, Kinoshita A, Wada E, Nomura S, Ohishi H, Takada M et al (1997). Differential presynaptic localization of metabotropic glutamate receptor subtypes in the rat hippocampus. J Neurosci 17: 7503-7522.

Shimazaki T, Iijima M, Chaki S (2004). Anxiolytic-like activity of MGS0039, a potent group II metabotropic glutamate receptor antagonist, in a marble-burying behavior test. Eur J Pharmacol 501: $121-125$.

Sik A, Penttonen M, Ylinen A, Buzsaki G (1995). Hippocampal CA1 interneurons: an in vivo intracellular labeling study. I Neurosci 15: 6651-6665.

Sik A, Ylinen A, Penttonen M, Buzsaki G (1994). Inhibitory CA1-CA3-hilar region feedback in the hippocampus. Science 265: $1722-1724$.

Silva AP, Xapelli S, Pinheiro PS, Ferreira R, Lourenco J, Cristovao $A$ et al (2005). Up-regulation of neuropeptide $\mathrm{Y}$ levels and modulation of glutamate release through neuropeptide $\mathrm{Y}$ receptors in the hippocampus of kainate-induced epileptic rats. J Neurochem 93: 163-170.

Śmiałowska M, Bajkowska M, Prezewlocka B, Maj M, Turchan J, Przewlocki R (1999). Effect of 6-hydroxydopamine on neuropeptide $\mathrm{Y}$ and corticotropin-releasing factor expression in rat amygdala. Neuroscience 94: 1125-1132.

Śmiałowska M, Sopala M, Tokarski K (1996). Inhibitory effect of intrahippocampal NPY injection on amphetamine-induced behavioural activity. Neuropeptides 30: 67-71.
Śmiałowska M, Wierońska JM, Szewczyk B (2003). Neuroprotective effect of NPY on kainate neurotoxicity in the hippocampus. Pol J Pharmacol 55: 979-986.

Śmiałowska M, Wierońska JM, Szewczyk B, Obuchowicz E (2002). Effect of some iono- and metabotropic glutamatergic ligands on neuropeptide $\mathrm{Y}$ immunoreactivity in the rat hippocampus. Pol J Pharmacol 54: 723-726.

Tatarczynska E, Kłodzińska A, Kroczka B, Chojnacka-Wójcik E, Pilc A (2001). The antianxiety-like effects of antagonists of group I and agonists of group II and III metabotropic glutamate receptors after intrahippocampal administration. Psychopharmacology (Berlin) 158: 94-99.

Tatarczynska E, Palucha A, Szewczyk B, Chojnacka-Wójcik E, Wierońska J, Pilc A (2002). Anxiolytic- and antidepressant-like effects of group III metabotropic glutamate agonist (1S,3R,4S)-1aminocyclopentane-1,3,4-tricarboxylic acid (ACPT-I) in rats. Pol J Pharmacol 54: 707-710.

Thorsell A, Michalkiewicz M, Dumont Y, Quirion R, Caberlotto L, Rimondini $\mathrm{R}$ et al (2000). Behavioral insensitivity to restraint stress, absent fear suppression of behavior and impaired spatial learning in transgenic rats with hippocampal neuropeptide $\mathrm{Y}$ overexpression. Proc Natl Acad Sci USA 97: 12852-12857.

Tizzano JP, Griffey KI, Schoepp DD (2002). The anxiolytic action of $\mathrm{mGlu} 2 / 3$ receptor agonist, LY354740, in the fear-potentiated startle model in rats is mechanistically distinct from diazepam. Pharmacol Biochem Behav 73: 367-374.

Tschenett A, Singewald N, Carli M, Balducci C, Salchner P, Vezzani A et al (2003). Reduced anxiety and improved stress coping ability in mice lacking NPY-Y2 receptors. Eur J Neurosci 18 143-148.

Tu B, Timofeeva O, Jiao Y, Nadler JV (2005). Spontaneous release of neuropeptide $\mathrm{Y}$ tonically inhibits recurrent mossy fiber synaptic transmission in epileptic brain. J Neurosci 25: $1718-1729$.

Vezzani A, Sperk G, Colmers WF (1999). Neuropeptide Y: emerging evidence for a functional role in seizure modulation. Trends Neurosci 22: 25-30.

Vianna MR, Coitinho AS, Izquierdo I (2004). Role of the hippocampus and amygdala in the extinction of fear-motivated learning. Curr Neurovasc Res 1: 55-60.

Vignes M, Clarke VR, Davies CH, Chambers A, Jane DE, Watkins JC et al (1995). Pharmacological evidence for an involvement of group II and group III mGluRs in the presynaptic regulation of excitatory synaptic responses in the CA1 region of rat hippocampal slices. Neuropharmacology 34: 973-982.

Wahlestedt C, Reis DJ (1993). Neuropeptide Y-related peptides and their receptors - are the receptors potential therapeutic drug targets? Annu Rev Pharmacol Toxicol 33: 309-352.

Wierońska JM, Śmiałowska M, Branski P, Gasparini F, Kłodzińska A, Szewczyk B et al (2004). In the amygdala anxiolytic action of mGlu5 receptors antagonist MPEP involves neuropeptide Y but not GABAA signaling. Neuropsychopharmacology 29: 514-521.

Wierońska JM, Szewczyk B, Palucha A, Branski P, Śmiałowska M (2003). Involvement of CRF but not NPY in the anxiety regulation via NMDA receptors. Pol J Pharmacol 55: 1119-1124.

Wierońska JM, Szewczyk B, Palucha A, Branski P, Zieba B, Śmiałowska M (2005). Anxiolytic action of group II and III metabotropic glutamate receptors agonists involves neuropeptide $\mathrm{Y}$ in the amygdala. Pharmacol Rep 57: 734-743.

Yoshimizu T, Shimazaki T, Ito A, Chaki S (2006). An mGluR2/3 antagonist, MGS0039, exerts antidepressant and anxiolytic effects in behavioral models in rats. Psychopharmacology (Berlin) 186: 587-593.

Young III WS, Bonner TI, Brann MR (1986). Mesencephalic dopamine neurons regulate the expression of neuropeptide mRNAs in the rat forebrain. Proc Natl Acad Sci USA 83: 9827-9831. 